\title{
A pronounced Eu anomaly in dissolved seawater REE patterns close to the Mid-Atlantic Ridge
}

\author{
SEAN SELZER ${ }^{1}$, YU-TE ALAN HSIEH ${ }^{1}$, PHIL HOLDSHIP ${ }^{1}$, \\ JOSEPH A RESING ${ }^{2}$, ALESSANDRO TAGLIABUE ${ }^{3}$, \\ AMBER ANNETT ${ }^{4}$, WILLIAM B HOMOKY ${ }^{5}$ AND GIDEON \\ M HENDERSON $^{1}$ \\ ${ }^{1}$ University of Oxford \\ ${ }^{2}$ University of Washington \\ ${ }^{3}$ University of Liverpool \\ ${ }^{4}$ University of Southampton \\ ${ }^{5}$ University of Leeds \\ Presenting Author: sean.selzer@earth.ox.ac.uk
}

The concentrations of Rare Earth Elements (REEs) in the ocean reflect riverine, aeolian and hydrothermal inputs as well as internal cycling, removals, and transport. The chemical behaviour of this set of elements is generally similar but with subtle, predictable variations, which allow us to separate entangled physicochemical processes. Hydrothermal fluids are enriched in REEs with respect to seawater, particularly in Eu, but due to efficient scavenging by plume particles, hydrothermal vents are considered a net sink for REEs in the ocean, and an unlikely influence on wider seawater REE patterns [1]. Elderfield et al., however, hypothesised that the $\mathrm{Eu} / \mathrm{Sm}$ ratio might record hydrothermal input to seawater [2]; Europium anomaly $\left(\mathrm{Eu} / \mathrm{Eu}^{*}\right)$ could be used to similar effect [3]. Our ability to assess the impact of hydrothermalism on Atlantic REE distributions has long been hindered by a paucity of dissolved REE measurements near hydrothermal vent sites.

Here we present dissolved REE concentrations in deep water samples, collected from the GA13 transect at a number of vent sites along the Mid-Atlantic Ridge (MAR), and measured by Elemental Scientific seaFAST ICPMS.

We reveal strong excursions in $\mathrm{Eu} / \mathrm{Eu}^{*}$ at depths in the water column that are coincident with excursions in the plume tracers dissolved $\mathrm{Mn}$ and ${ }^{3} \mathrm{He}$ at $\mathrm{TAG}$ vent site. Plume $\mathrm{Eu} / \mathrm{Eu}^{*}$ excursions are also present $30 \mathrm{~km}$ from the main vent site, providing evidence that the strong $\mathrm{Eu}$ anomaly present in TAG hydrothermal fluids is not wholly removed from the dissolved fraction by plume scavenging processes, and may impact REE patterns farther afield. $\mathrm{Eu}$ anomalies will be discussed in the context of wider Atlantic observations and used to investigate the utility of $\mathrm{Eu} / \mathrm{Eu}^{*}$ as a record of hydrothermal input to seawater.

References:

[1] Elderfield, Whitfield, Burton, Bacon, and Liss (1988). Philosophical Transactions of the Royal Society A: Mathematical, Physical and Engineering Sciences 325(1583), $105-126$.

[2] Grenier, Garcia-Solsona, Lemaitre, Trull, Bouvier, Nonnotte, Van Beek, Souhaut, Lacan and Jeandel (2018). Frontiers in Marine Science 5, 426.

[3] Mitra, Elderfield and Greaves (1994). Marine Chemistry 46(3), 217-235. 